\title{
Productivity Improvement by using Time Study Analysis and Modern Trends in Manufacturing Industry
}

\author{
Jaydip Katkar, Vishal wakade, Arati Supekar, Kalyani Sankpal, Ankita Shimpi
}

\begin{abstract}
The productivity of any organization can be increased by optimizing the work process. Low productivity of workers is one of the reason behind the delay in delivery in manufacturing sector we know that in manufacturing sector labor is prominent thing. Improving the productivity means to make the best possible use of available resources and achieve maximum output. This paper focuses on the productivity of machine as well as labor by using fixtures, updated systematic layout and use of material handling equipment. This paper also covers the, what is productivity, which factors are affecting on productivity and efficiency. Maximum efficiency or productivity is trademark of any successful organization The objective of this paper is to identify the problem in medium scale industry due to time and effort required for any operations is high To tackle and understand a detailed analysis regarding processes using time study and work study. Due to implementation of all the measures the productivity of an organization is increases resulting in reduced effort and time required for operation and all operations done optimally.

Keywords: productivity, fixture, Time study, work study
\end{abstract}

\section{INTRODUCTION}

Now a days the demand of product are increases, for fulfilling that demand industries must increases there potential it becomes need of hour. Potential in the sense the productivity. Productivity is most and biggest challenge in front of industries. Productivity measure combined employees, machines, and equipment which is used in for carried out that operation.

According to Peter F Drucker, "productivity means all factors of production that will give the maximum output with smallest effort." for improving the productivity there are several technique such as TQM, QC, time study, method study, design of plant layout etc. for improving productivity in small scale industry we was think on jig and fixture arrangement for manufacturing component, design of

Revised Manuscript Received on May 15, 2020.

* Correspondence Author

Jaydip Katkar*, School of mechanical and civil engineering, MIT Academy of Engineering, Pune, India. Email: jkkatkar@mitaoe.ac.in

Vishal Wakade, School of mechanical and civil engineering, MIT Academy of Engineering, Pune, India. Email: vdwakade@mitaoe.ac.in

Arati Supekar, School of mechanical and civil engineering, MIT Academy of Engineering, Pune, India. Email: aratisupekar6212@gmail.com

Kalyani Sankpal, School of mechanical and civil engineering, MIT Academy of Engineering, Pune, India.

Email: Kalyani.sankpal1999@gmail.com

Ankita Shimpi, School of mechanical and civil engineering, MIT Academy of Engineering, Pune, India. Email: ankitashimpi19@gmail.com

(c) The Authors. Published by Blue Eyes Intelligence Engineering and Sciences Publication (BEIESP). This is an open access article under the CC BY-NC-ND license (http://creativecommons.org/licenses/by-nc-nd/4.0/) facility, time study and method study, material handling technique.

Time study and automatic jig and fixture arrangement reduces the time required for carried out that operation (drilling, milling, and reaming).and due that automatically productivity increases and effort required for that operation is reduces.

Objective of research:

1. Identify the proposed methodology which reduces manufacturing lead time.

2. Improve productivity by implementing new method.

3. Improve the plant layout to utilizing them in an effective manner.

\section{LITERATURE REVIEW}

1.The research paper titled as 'The research Improvement in Line Feeding System in Assembly Plant using Lean Manufacturing Technique', whose authors are Varsha Karandikar, Shriram Sane, Rahul Pulkurte expressed their thoughts as, Planning and designing of manufacturing processes plays vital role in optimum productivity by utilizing maximum resources with low production cost. The main objective of the paper is to implementation of industrial engineering tools in paint industry. To reduce unnecessary movements of labors and tools .Time study method, method study and layout study techniques used. There were some suggestions which proposed how to replace old packaging method by the use of zip ties which requires less manpower and results in productivity improvement of the manufacturing industry.

2. The research paper titled as 'Productivity Improvement Using Time Study Analysis In A Small Scale Industry 'whose authors, Sai Nishanth Reddy, P. Srinath expressed their thoughts as, To improve productivity of manufacturing industry motion and time study tech que is used. Also there are various factors which influence the productivity of manufacturing organization .The major issue is that how to improve efficiency and as well as productivity. Also assembly line is also major area which is to be considered for productivity improvement. The main aim of this paper is to discuss problem faced during implementation of motion and time study and its impacts on productivity improvement. To achieve maximum productivity small scale solar appliances proves that the motion and time study implementation and assembly line balancing plays huge role. 3. The research paper titles as 'Productivity Improvement by Work Study Technique: A Case on Leather Products Industry of Bangladesh', whose authors are Md.

Published By:

Blue Eyes Intelligence Engineering \& Sciences Publication
(C) Copyright: All rights reserved. 
Abdul Moktadir, Fatema -Tuj-Zohra, Sobur Ahmed, Razia Sultana expressed their thoughts as, In leather products industry, work study is most important tool which helps to improve productivity.

The profit eating as leather products industry laglet depends on productivity improvement. Also finding the gap of productivity prices and operations, this study helps. In this paper there were one suggestion i.e. Lean manufacturing concept could be used for our work. This study shows that the productivity improvement by reduction of work content and balancing line.

\section{METHODOLOGY}
a) Painting Operation.
b) Drilling Operation.
c) Reaming operation.
d) Facility layout.
e) Material handling
f) Gang Milling Operation.

\section{a) Painting operation:}

The objective of painting is to form a coating film on the surface of an object in order to

Protect the object and give a fine appearance. Painting may also have other special

Functions. In the painting operation, various types of painting methods are used according to the

Shape, size, quality, and quantity of the objects to be painted.

The painting on jobs is done by Brush painting manually. Paint brushes are also the perfect tool for covering up and blemishes from general wear-and-tear. Naturally, to use a paint brush to apply paint to the entire exterior of a job/part is not recommended as this will be inefficient in terms of materials, labor, and time. This would also likely leave brush marks and a finish that is not as smooth as some alternatives. It requires more time and the coating of paint is not proper which decreases the productivity.

There are several methods of painting like Air Spray painting, Roller, Dip coating and Airless painting method. Although spray painting can be used here which will make significantly reduce the time required for painting. Spray painting is a painting technique where a device sprays a coating through the air onto a surface. Spray painting should always be done in a well-ventilated spray booth defined as a 'separate room with a ventilation system'. Spraying of sealer, basecoat, and clear coat is almost always done in a spray booth to protect both the workers and the paint job.

Industrial spray painting can cover a large area, very quickly. This can reduce the time it takes to do a job, minimizing downtime for your job, as well as reducing the cost of the job. Industrial spray painting systems give a smooth and even finish, which can withstand wear and tear as well as harmful corrosion. This reduces the defects as well as time and increases productivity.

\section{b) Drilling machine}

Jobs drilled on drilling machine are of batch type i.e. not same type of job are drilled every time. When the workers were not used fixture for the job the time required for drilling is more and thus the productivity is decreases

Fixture us the special tool used for holding the work piece in proper position during manufacturing operation. A fixture consist of set of locator are used to deter mine the position and orientation of work piece, were clamps exert clamping force so that the work piece is pressed firmly against locators. After using of the fixture to hold the job the time required to drill is reused and the productivity increases.

\section{Table No 1:}

Machine 1.

\begin{tabular}{|l|l|l|}
\hline SR. No & $\begin{array}{l}\text { Time required } \\
\text { With fixture (sec) }\end{array}$ & $\begin{array}{l}\text { Time required } \\
\text { Without } \\
\text { (sec) }\end{array}$ \\
\hline 1. & 85 & 65 \\
\hline 2. & 84 & 64 \\
\hline 3. & 86 & 66 \\
\hline 4. & 86.4 & 66.4 \\
\hline 5. & 84.5 & 64.5 \\
\hline 6. & 87 & 67 \\
\hline 7. & 86.7 & 66.7 \\
\hline 8. & 85.8 & 65.8 \\
\hline 9. & 86.8 & 66.8 \\
\hline 10. & 85.5 & 65.5 \\
\hline Average time & 85.77 & 65.77 \\
\hline
\end{tabular}

From above table it is clearly indicate that time required for doing job without automatic fixture is larger than with fixture arrangement.

Time required without automatic fixture arrangement:- 85.77 $\mathrm{sec}=86 \mathrm{sec}$

Time required with automatic fixture arrangement:- 65.77 sec $=66 \mathrm{sec}$

\section{Calculation:-}

When per job $20 \mathrm{sec}$ time is reduces so productivity (quantity) is increases by 12 /hour. When considered with (percentage) $=22.22$

So this paper shows that automatic fixture arrangement increases productivity.

\section{C) Reaming operation:}

In industry reaming operation is performed for a particular part of shackle to enlarge the size of a previously formed hole by a small amount but with high degree of accuracy to leave smooth sides. Material handling takes more time as well as more human efforts due to this productivity goes on decreasing. While setting down the component on table it is necessary to fit component properly for better performance and safety purpose.

The daily increase of competition among part makers has necessitated a higher rate of productivity. Automation, as a major factor influencing productivity has an undeniable role in the drive for higher quality and lower prices. Automatic transfer of components between reaming machine by loading and unloading system and robots is an automation trend to increases speed and performance.

Also fixture with less moving parts but having better performance helps to reduce time required to fit the component properly within a few seconds. With the help of this time required to fix and loose the components decreases and productivity increases.

Table no.2
Published By:

Blue Eyes Intelligence Engineering \& Sciences Publication

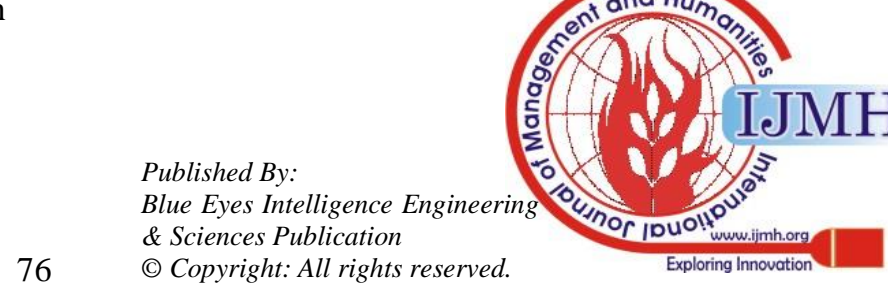




\section{Readings of Reaming Operation Performed}

\begin{tabular}{|c|c|c|}
\hline Sr. No. & $\begin{array}{l}\text { Time required for } \\
\text { reaming with } \\
\text { traditional } \\
\text { method } \\
\text { (Sec) }\end{array}$ & $\begin{array}{lr}\text { Time required for } \\
\text { reading } \\
\text { automatic fixthre } \\
\text { arrangement } \\
\text { (Sec) }\end{array}$ \\
\hline 1 & 98 & 64 \\
\hline 2 & 97 & 63 \\
\hline 3 & 101 & 63.5 \\
\hline 4 & 99.2 & 64.1 \\
\hline 5 & 96.1 & 64 \\
\hline 6 & 100 & 65 \\
\hline 7 & 102 & 64.5 \\
\hline 8 & 97.5 & 63 \\
\hline 9 & 98.8 & 64 \\
\hline 10 & 100.02 & 65 \\
\hline Average & 98.96 & 64.01 \\
\hline
\end{tabular}

Table no .3

\section{Observation Table:}

\begin{tabular}{|l|l|l|}
\hline $\begin{array}{l}\text { No. Of } \\
\text { Working Hours }\end{array}$ & $\begin{array}{l}\text { Parts manufactured } \\
\text { without Jig and } \\
\text { fixture }\end{array}$ & $\begin{array}{l}\text { Parts manufactured } \\
\text { with jig and fixture }\end{array}$ \\
\hline 1 & 39 & 50 \\
\hline 8 & 312 & 400 \\
\hline
\end{tabular}

\section{Calculations:}

i. Current productivity without using jig and fixture :

Productivity $1=$ Output/ Input

$312 / 8=39 \%$

ii. Improved productivity by using jig and fixture:

Productivity 2 = New output $/$ New Input $400 / 8=50 \%$

iii. To get improved productivity:

Productivity 2 - Productivity 1= Improved Productivity

$50-39=11 \%$

iv. To calculate productivity improvement rate in percentage:

(Productivity improvement / Productivity 1$) \times 100=$ $\%$ Increases

$$
(11 / 39) * 100=28.20 \%
$$

When we use automated jig and fixture arrangement for reaming operation then productivity rate increases by $28.20 \%$ per day.

D) Facility layout:-

The way of arrangement of machines and material define the layout. While increasing productivity of any company facility layout plays very vital role.

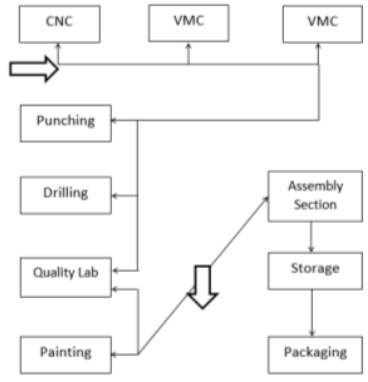

Figure. 1 Proposed facility layout

Following observation were made in proposed layout Total distance travelled $=22 \mathrm{~m}$

Average speed of the worker $=0.8 \mathrm{~m} / \mathrm{s}$

Time required $=27.5 \mathrm{~min}$

\section{Existing plant layout:-}

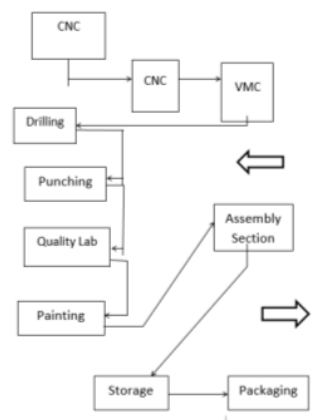

Figure.2 Existing facility layout

Following observation were made in proposed layout Total distance travelled $=27$

Average speed of the worker $=0.8 \mathrm{~m} / \mathrm{s}$ Time required $=33.75 \mathrm{~min}$

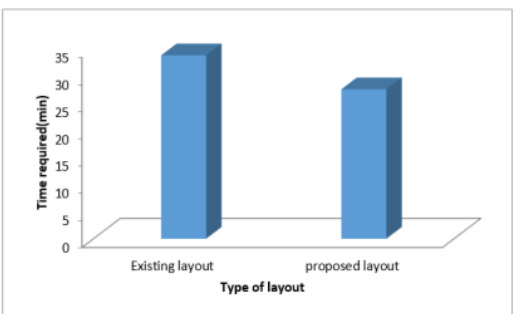

Figure.3 Bar graph, Time requirement vs Type of layout

Form graph it is clearly indicate that time required for doing one job is greater by existing layout. This paper shows that time required by new proposed layout is less than exiting layout.

Calculation:-

For one job=27.5 min (proposed layout)

For one job=33.75 min (existing layout)

Job production in one shift=nearby 15

Job production in one shift=nearby 12

Job production three shift $=45$

Job production in three shift $=36$

So form that calculation paper shows that nearby $20 \%$ productivity is increases with proposed layout.

Blue Eyes Intelligence Engineering \& Sciences Publication
Published By:

and $\mathrm{Hu}_{4}$

(C) Copyright: All rights reserved. 
e) Material handling:-

Proposed solution regarding material handling system. Currently such type of containers are used for moving completed/uncompleted job as they are not easy to lift while moving it while it is loaded with jobs. Worker needs to bend and lift the container of weight approximately 10 kilograms depending upon number of jobs so we are proposing solution as a utility wagon which are easy to use and it also generate less fatigue in workers muscles.

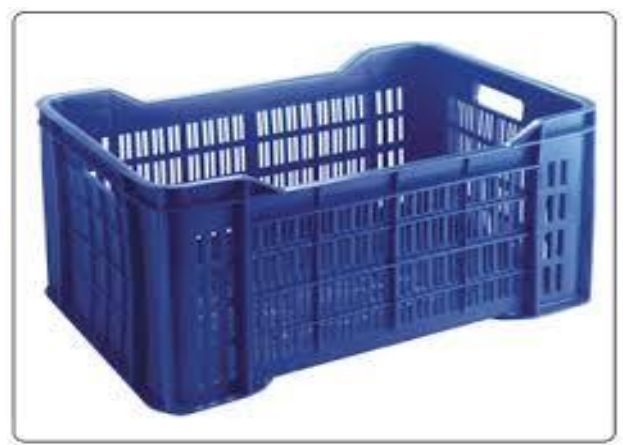

Figure. Current material handling for jobs

The proposed material handling system not only reduce the fatigue as well as it has increased load carrying capacity compared to current one.

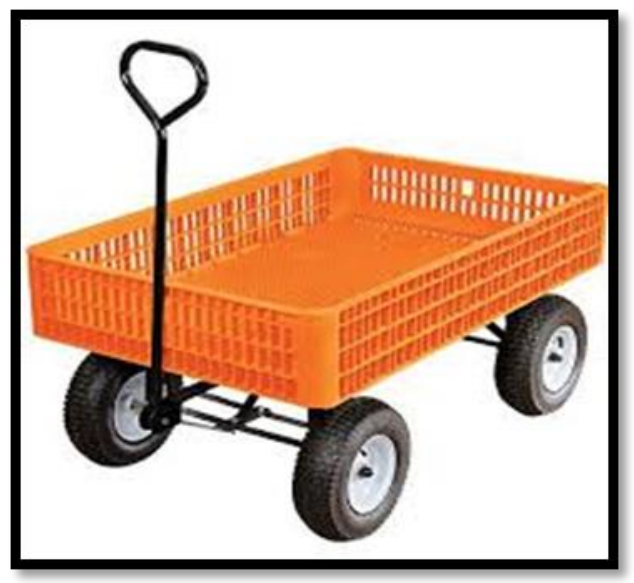

Figure. Proposed Material handling system

\section{f) Clamping fixture for gang milling of job:}

Now only one job is machined at a time after that it needs to be unclamped so the other job should be clamped this adds delay in production as well as machine remains idle during this time so solution for this is the new clamping fixture which can be used to clamp four number of jobs at a time and total time required for clamping and unclamping will be less than compared to time required for clamp and unclamp the four job by current method it will reduced by nearly $50 \%$ compared to previous time.

After completion of one job the part of fixture could be rotated so that next clamped job could be brought in position for gang milling.
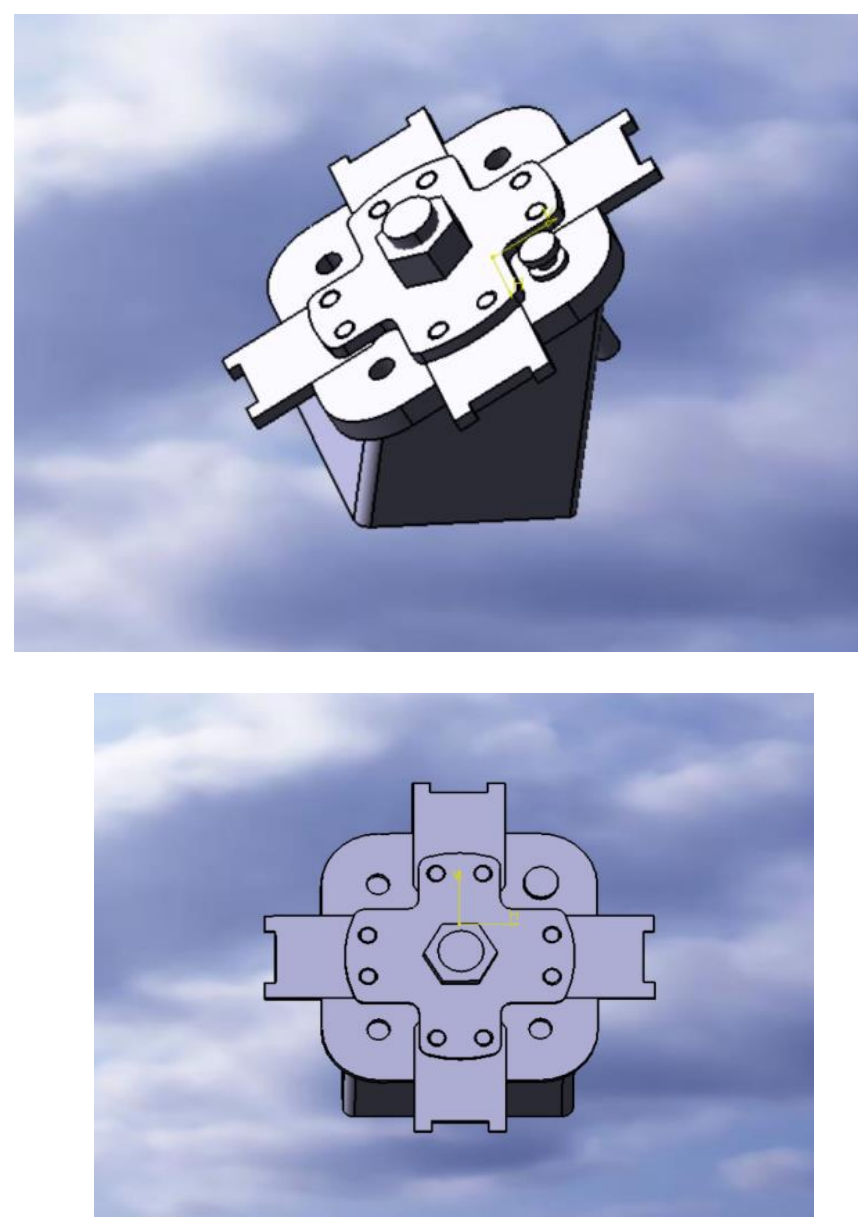

Figure. Fixture for gang milling

Calculation:-

\begin{tabular}{|l|l|l|l|l|l|}
\hline $\begin{array}{l}\text { SR. } \\
\text { No }\end{array}$ & $\begin{array}{l}\text { Clamping } \\
\text { time } \\
(\text { Sec })\end{array}$ & $\begin{array}{l}\text { Unclamping } \\
\text { time (Sec) }\end{array}$ & $\begin{array}{l}\text { Operation } \\
\text { time(sec) }\end{array}$ & $\begin{array}{l}\text { Total } \\
\text { time(Sec) }\end{array}$ & $\begin{array}{l}\text { Total } \\
\text { time } \\
\text { saved }\end{array}$ \\
\hline 1 & 26 & 14 & 66 & 106 & 30 \\
\hline 2 & 28 & 15 & 65 & 108 & 32.25 \\
\hline 3 & 30 & 17 & 65 & 112 & 35.25 \\
\hline 4 & 27 & 15 & 64 & 106 & 31.5 \\
\hline 5 & 29 & 18 & 68 & 115 & 35.25 \\
\hline 6 & 30 & 19 & 71 & 120 & 36.75 \\
\hline 7 & 27 & 18 & 72 & 117 & 33.75 \\
\hline 8 & 28 & 16 & 68 & 112 & 33 \\
\hline 9 & 27 & 17 & 66 & 110 & 33 \\
\hline 10 & 29 & 18 & 65 & 112 & 35.25 \\
\hline
\end{tabular}

Average total operation time $=111.8 \mathrm{sec}$ (Traditional method) Average operation time is $=67.3 \mathrm{sec}+20 \mathrm{sec}=87.3 \mathrm{sec}$ (proposed method)

Average total time save $=24.5 \mathrm{sec}$

Jobs produced in one shift $=214$ unit (traditional method) Jobs produced in one shift $=274$ unit (proposed method)

Productivity increases in \%=21 approx.

\section{RESULT ANALYSIS}

1. In drilling operation due to use of automatic fixture arrangement the productivity is nearly increases by $22 \%$.

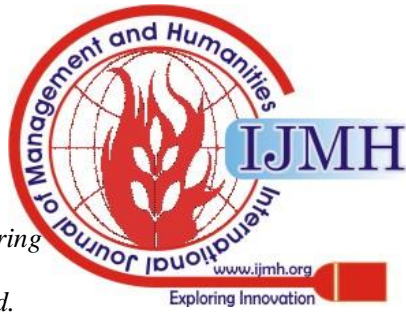


2. In reaming operation due to use of automatic fixture arrangement the productivity is nearly increases by $28 \%$.

3 . This paper shows that due to implementation of proposed layout productivity is nearly $20 \%$ increases.

4. Due to fixture arrangement for gang milling increases $21 \%$ 5 . This paper shows that the proposed system is very efficient and due to this effort required for carried out any operation is reduced.

\section{CONCLUSION}

For progress of any organization, it is very important to identify and understand various factors that influence on the growth of the industry. Workers productivity is one very important which influence most. Based upon the results, it can be concluded that the process can be improved based on method study, time study, work procedure and proper utilization of machine and material. This paper also shows that the effort required for doing some operation is also reduces due to implementation propose material handling technique. After implementing the suggested improvement ideas, the industry is able to increases the productivity i.e near by $22 \%$.

\section{REFERENCES}

1. Md Abdul Moktadair and Sobur Ahmed "Productivity Improvement by Work Study Technique",A Case on Leather Products Industry of Bangladesh. Research Gate January, 2017

2. Varsha Karandikar, Shriram Sane and Rahul Pulkute "Improvement in Line feeding System in Assembly Plant using Lean Manufacturing Techniques"International Journal of Current Engineering and Technology, May 2014.

3. Aakash Jaiswal, Shri Ram Madhukar Sanet and Varsha Karandikar "improve the productivity in Paint industry using engineering tools and Techniques" International Journal of Advance Industrial Engineering. March 2016

4. Ali Rafiei, Seyed Mahdi Homayouni and Amir Shafiei Alavijeh"A Mathematical Model for the Single Machine Scheduling Considering Sequence Dependent Setup Costs and Idle Times" Applied Research on Industrial engineering, 2015

5. Parthiban.P and Raju.R"Productivity improvement in shoe making industry by using method study"IOSR Journal of Mechanical and Civil Engineering

6. Sumit Salunke, Sujeet Sirame, Madhura Mali, Sandesha Rathod and Prof.V.P. Kulkarni"Improving Productivity in a Mechanical Industry using Industrial Engineering Tools and Techniques" International Research Journal of Engineering and Technology, April 2019

7. Vatsal Singh, Sharvari Nalawade, Ashish Dhongade and Sandeep Bera"Productivity Improvement by Time Study Analysis Moderate Scale Industry - Manufacturing of Cutting Tools "International Research Journal of Engineering and Technology April 2019

8. Mayank Dev Singh, Shah Saurabh K, Patel Sachin B, Patel Rahul B \& Pansuria Ankit P"To Improve Productivity By Using Work Study \& Design A Fixture In Small Scale Industry”, Research Gate, December 2012

\section{AUTHORS PROFILE}

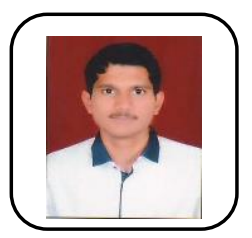

Jaydip katkar A, STUDENT Pursing B.TECH in Mechanical Engineering in MIT academy of Engineering, Pune from 2018.Completed diploma in Mechanical Engineering from SVERI College Pandharpur with first class with Distinction. Published paper on "Automatic Water Level Management System Controlled by using Arduino, Ultrasonic and Water Level Sensor and TDS effect by TDS Sensor "on IJRAR. Got best outgoing student award at school as well as college level. Currently working on the project "Arduino operated an autonomous planter by using capillary bed phenomenon with the help of micro-irrigation (inline). Completed one month internship in automobile industry. Certification in basic python course of MICHIGAN University. Certification in project management for manager's course which is held by NPTEL.Completed financial marketing course certified by YALE

University. Mainly interest in sales and finance and industrial engineering and management.

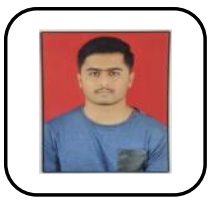

Vishal Wakade, student of B.Tech in mechanical engineering at Mit academy of engineering, Pune, India completed diploma in mechanical engineering from Government Polytechnic Osmanabad. Having work experience in motorsports clubs and been a member of college go karting team (Niyudrath Karting) for two years along with this has worked in central railway workshop in sections like maintenance, narrow gauge, broad gauge and cartridge taper roller bearing member of college photography club shutterbug MITAOE. Completed projects on solar bicycle, automatic parking system, and multipurpose tool handle, digital planter, steering wheel hub etc. Certification in CAD software's and project management for managers from NPTEL.

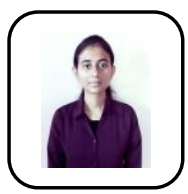

Arati Supekar, A student pursuing BTech in Mechanical Engineering in MIT Academy of Engineering, Pune from 2018. Completed Diploma in Mechanical Engineering from Government Polytechnic, Pune with first class Distinction. Currently working on' Grass Chopper Machine as a mini project'. Successfully completed the project on' Maintenance on Hydraulic Dynamometer Of Four Stroke Four Cylinder Petrol Engine' at diploma level. Working on a research topic of 'IOT Based Garbage Monitoring System' as well as 'Grass Chopper Machine'. Has a working experience of 30 days as an intern. Certification in the course Project Management for managers. Successfully completed a workshop on Coding and Debugging as well as Applications Of IOT In automation. The areas of interest are automobile, Mechanical Designing and Automation.

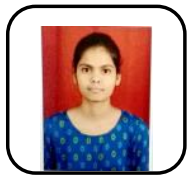

Kalyani Anil Sankpal., A student pursuing B.Tech in Mechanical Engineering in MIT Academy of Engineering, Pune from 2018. Completed Diploma in Mechanical Engineering from Government Polytechnic, Pune with first class Distinction. Certified in project management from NPTEL and of Python from Coursera. Successfully complete project Road safety System using Arduino microcontroller and also prototype of carbon nanotubes production for environmental science. Completed an internship for duration of 30 days mainly interested in Quality control, Humans resource and Mechanical design area.

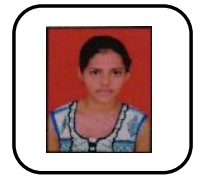

Ankita Shimpi A, student pursuing BTech Mechanical engineering in MIT Academy of Engineering Alandi, Pune. Completed diploma in mechanical engineering from Government polytechnic Pune with first class distinction. Working experience in projects such as Prototype of Automated parking system (IOT base), Road safety system (IOT base) and Repair and maintenance of Air Conditioner. Completed an internship for the duration of 30 days in fabrication firm. Certification in the course Project management for managers. Certification in the course Python language. Interested to work in mechanical design, quality control, and automobile sector
Published By: Blue Eyes Intelligence Engineering \& Sciences Publication

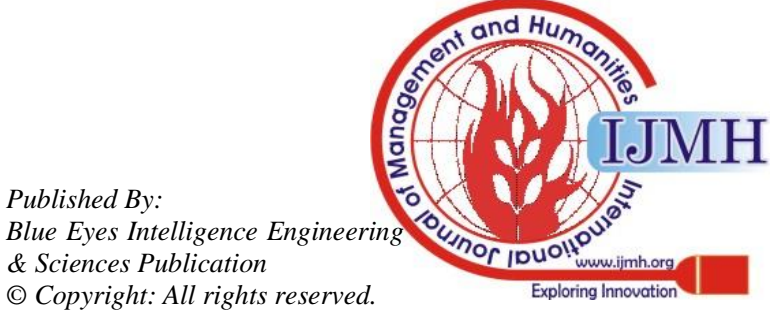

